\title{
LINEAMIENTOS PARA LA DEFINICIÓN \\ DE UN MODO DE CRECIMIENTO URBANO SOSTENIBLE. El Caso de Mendoza (Argentina), provincia de tierras secas
}

\author{
Autor: Mariana Silvina Sammartino \\ Universidad o Institución a la que pertenece: Universitat Internacional de Catalunya \\ Director de la tesis en curso o de la investigación: Dra. Arq. María del Carmen Mendoza Arroyo \\ E-mail: msammartinoarq@yahoo.com.ar / msammartinoarq@gmail.com
}

\section{RESUMEN}

Actualmente, la globalización está generando procesos territoriales que modifican sustancialmente los sistemas urbanos.

En Mendoza, los procesos de ocupación han generado un territorio fragmentando producto de la interacción histórica naturaleza-sociedad, existiendo espacios dominantes (los oasis) sobre otros dominados (las tierras secas no irrigadas).

Esto ha producido un modelo territorial de concentración difusa desequilibrada, reflejo de una región subdesarrollada con una estructura espacial muy jerarquizada y un predominio de urbanización difusa, fuertemente concentrada en los oasis. Sólo el 3\% de la superficie provincial de tierras secas posee riego donde, gracias a la sistematización y el aprovechamiento integral del agua, conviven los centros urbanos y las actividades productivas.

Por presentar las ciudades como modo preponderante de crecimiento la extensión de la mancha urbana sobre las escasas tierras secas irrigadas, se procede a formular lineamientos tendientes a definir un modo de crecimiento urbano sostenible para Mendoza, provincia de tierras secas.

Palabras clave: procesos territoriales, ordenamiento territorial, tierras secas, crecimiento urbano sostenible.

\begin{abstract}
Currently, globalization is creating processes that substantially alter territorial urban systems.

In Mendoza, the processes of occupation have generated a territory fragmenting product of the historical interaction between nature and society, existing dominant spaces (oases) dominated over other (nonirrigated drylands).

This has been a model of unbalanced territorial concentration diffuse reflection of an underdeveloped region with a very hierarchical spatial structure and a predominance of urban sprawl, heavily concentrated in the oases. Only $3 \%$ of the provincial surface irrigation has drylands where, thanks to the systematic and comprehensive use of water, urban centers and live productive activities.

By presenting the cities as dominant growth mode expansion of the urban area on the few irrigated drylands, we proceed to develop guidelines aimed at defining a sustainable way of urban growth for Mendoza province dryland.
\end{abstract}

Key words: territorial processes, land use, drylands, sustainable urban growth. 


\section{LA INTERACCIÓN ESPACIO-SOCIEDAD EN LA CONFIGURACIÓN DEL TERRITORIO}

Abordar la configuración del territorio implica partir de la concepción de que la naturaleza está mediada socialmente y que las relaciones sociales operan en una estructura natural, con la que interactúan permanentemente. Este pensamiento otorga un marco global que permite analizar la forma en que la sociedad transforma la naturaleza, con el objetivo de elevar su calidad de vida (Montaña, 2008).

Esta transformación se realiza a través de la racionalidad impuesta por una formación económica y social, la que imprime una determinada modalidad al proceso de transformación, determinando un destino social de la producción (para quién se produce), una forma tecnológica (cómo se produce), un hábito determinado de producción (dónde se produce) y una demanda de recursos naturales y hábitat (con qué recursos naturales se produce).

Los avances tecnológicos de los últimos siglos crearon el espejismo de poder asegurar el bienestar de la población mediante el dominio de las fuerzas de la naturaleza, lo que trajo aparejado graves desequilibrios ecológicos y sociales. A principios del Siglo XXI, la humanidad se enfrenta a severos problemas de índole ambiental, entre ellos la crisis del agua.

\subsection{Las interacciones espacio-sociedad configuradoras de Mendoza, una provincia de tierras secas} Elma Montaña (2008:3) sostiene que "si para comprender los procesos de configuración territorial se deben analizar las relaciones espacio-sociedad, en las tierras secas se debe prestar también atención a las relaciones naturaleza-cultura; es decir, a la manera en la que los grupos sociales se vinculan con la naturaleza para construir su hábitat (en sentido amplio), para desarrollar sus procesos productivos y para reproducirse y desarrollarse como sociedad". Por lo mencionado, la producción de hábitat es un proceso que, aunque difuso en su traza espacial, es muy elocuente respecto de las relaciones espacio-sociedad y naturaleza-cultura en el marco de los cuales los recursos son diferencialmente apropiados y los territorios disputados en estas tierras secas.

En las zonas áridas, la producción de asentamientos humanos y su articulación en sistemas urbanos así como la configuración de los ámbitos rurales, se encuentra estrechamente ligada a la presencia de agua.

Tomando a Mendoza como caso puede decirse que la misma, tal como se la observa en la actualidad, es el producto de procesos de interacción naturaleza-sociedad desarrollados a lo largo de más de 500 años. En esta larga historia, el factor central lo constituye el manejo de los recursos hídricos escasos, el que consiste en haber desarrollado históricamente un sistema que se basa en la captación y distribución del agua superficial, la perforación de pozos para el bombeo del agua subterránea y el armado del andamiaje institucional que regula el uso de ambos (Montaña, 2004).

En la escala regional, la resultante de este aprovechamiento hídrico ha dado por resultado un territorio fragmentado en el que los oasis artificiales de riego aparecen como islas en un vasto espacio desértico.

Por lo antedicho, quedan francamente definidos dos territorios contrastivos con paisajes bien diferenciados: los verdes oasis (forjados por el trabajo del hombre ante una naturaleza árida) y el desierto (espacios subordinados percibidos como vacíos y despoblados).

Al igual que los oasis, los centros urbanos también están construidos para hacer ostentación del dominio del hombre sobre el recurso hídrico. El $\mathrm{AMM}^{1}$ en particular puede ser considerada una ciudad-bosque por su sistema calle-acequia / vereda-árbol (Montaña, 2006c), configurando los espacios abiertos de esta ciudad de zona semi-árida.

Conforme a lo antedicho, el manejo de los recursos hídricos se ha mostrado como estructural no sólo en la modelación de esta sociedad de tierras secas, sino también en la configuración de sus espacios urbanos, de los oasis que produce y de los espacios desérticos que torna invisibles. El manejo del agua resulta clave en la articulación entre esa sociedad y esos espacios.

Podría decirse que a lo largo del tiempo se han producido determinadas y particulares relaciones entre naturaleza y sociedad, definidoras de una serie de procesos que han configurado a los territorios de maneras muy peculiares, lo que puede observarse en las tierras secas y, específicamente, en Mendoza.

Esto permite vislumbrar la existencia de una dimensión simbólica que se trasluce en un pensamiento hegemónico que ha configurado el territorio mendocino bajo dos lógicas: espacios dominantes, que reflejan el poder del hombre sobre la naturaleza (los oasis), y espacios dominados, invisibles producto de la demostración de ese poder (el desierto).

A partir de considerar esta interacción naturaleza-sociedad que ha significado históricamente un particular modo de habitar un lugar, se pueden identificar los procesos que han configurado un territorio dando por resultado un modelo territorial específico. En Mendoza, este modelo refleja una gran concentración de recursos y de funciones en las escasas superficies de los oasis.

\footnotetext{
${ }^{1}$ AMM: sigla utilizada para denominar el "Área Metropolitana de Mendoza", la que se conforma por las cabeceras de los departamentos de Capital, Godoy Cruz, Guaymallén, Luján, Las Heras y Maipú.
} 


\section{EL DESARROLLO SOSTENIBLE EN LOS ESPACIOS DE FRAGILIDAD AMBIENTAL: LAS TIERRAS SECAS}

Para los autores Pujadas y Font (1998), existen territorios que por su particularidad pueden encuadrarse dentro del grupo genérico de espacios con una vulnerabilidad o fragilidad especial, que requiere la adopción de medidas específicas de ordenamiento.

Concebidas las tierras secas como áreas de fragilidad ambiental, Elena Abraham (2008), sostiene que las mismas abarcan una amplia gama de soluciones ambientales, comprendiendo desde los desiertos extremos (hiperárido) hasta los ecosistemas subhúmedos secos.

Según la definición adoptada por la UNCCD (Convención Internacional de Naciones Unidas de Lucha contra la Desertificación y la Sequía), las tierras secas susceptibles de ser afectadas por la desertificación comprenden las regiones áridas, semiáridas y subhúmedas secas (excluidas las regiones polares y subpolares y el hiperárido) en las cuales el coeficiente de precipitación anual en relación con la evapotranspiración potencial, se extiende entre 0,05 y 0,65 (UNCCD/PNUMA, 1995). Siguiendo este marco, el principal problema ambiental que afecta a las tierras secas es la desertificación, causada por la variabilidad climática y por las actividades humanas. La desertificación ocurre porque los ecosistemas de tierras secas son sumamente vulnerables a la sobreexplotación y el aprovechamiento inadecuado de la tierra.

La palabra desertificación suele asociarse a la formación de desiertos pero por definición, la desertificación no es un problema de los desiertos: es la consecuencia de la sobreexplotación que los grupos humanos hacen de las tierras secas del planeta. El clima (fundamentalmente la recurrencia de fenómenos como las sequías) juega un papel catalizador pero no es determinante del proceso. Sí lo son las prácticas agrícolas inadecuadas, el sobrepastoreo, la pérdida de la biodiversidad, los procesos de urbanización, la expansión de la frontera agropecuaria, el mal manejo del recurso hídrico que favorece el anegamiento y la salinización de los suelos o los procesos de empobrecimiento de la población, que generan miseria y emigración de las áreas rurales a las urbanas.

La autora también sostiene que el mal manejo del recurso hídrico produce algunos de los más importantes procesos de desertificación, en un fenómeno mucho más complejo, donde la sequía es sólo uno de los componentes, y no el determinante de los procesos de degradación.

Además, actualmente se observan acelerados procesos de cambio en los usos del suelo que, sobrepasando a cualquier intento de planificación y ordenamiento, responden a intereses sectoriales y marginan a los más vulnerables del proceso de toma de decisiones.

La lucha contra la desertificación es imprescindible para garantizar la productividad a largo plazo de las tierras secas. Muchos esfuerzos han fracasado por la utilización de enfoques parciales, sin tener en cuenta la complejidad y múltiples relaciones causa-efecto del problema y, sobre todo, por no considerar que los pobladores de las tierras secas son su mayor recurso. Ellos conocen sus problemas y sus potencialidades y han desarrollado conocimientos, tecnologías y habilidades para producir en condiciones restrictivas.

Por todo lo mencionado, se reconoce la necesidad de establecer enfoques integrados para abordar la problemática de las tierras secas sosteniendo que "problemas semejantes tienen diferentes soluciones" (Abraham, 2008:3) y éstas deben basarse en principios básicos y generales, pero estar enfocadas en la realidad de cada país, de cada territorio, de cada sociedad a fin de lograr su desarrollo sostenible.

\subsection{Mendoza, una provincia de tierras secas: caracterización}

La provincia de Mendoza está situada en el centro-oeste del país, entre los $32^{\circ}$ y $38^{\circ}$ de latitud Sur y entre los $67^{\circ}$ a los $70^{\circ}$ de longitud Oeste, a una altura media de $720 \mathrm{~m}$. sobre el nivel del mar, con una superficie de $150.839 \mathrm{Km}^{2}$. Participa con el 5,4\% del territorio nacional.

Varias Rutas Nacionales la conectan internacional, nacionalmente y con la Región de Cuyo, como lo son las $\mathrm{RN} \mathrm{N}^{\circ}$ 7, 40, 143 y 188. Cabe aclarar que Mendoza es la puerta hacia Chile a través del Paso Internacional Cristo Redentor lo que la posiciona en un lugar de privilegio dentro del Corredor del Mercosur.

Por encontrarse ubicada dentro de la Diagonal Árida de la República Argentina, se halla constituida por tierras secas las que se discriminan en tierras secas irrigadas y no irrigadas, según la disponibilidad de agua.

Haciendo referencia al Subsistema físico-natural y desde el punto de vista climático, por estar localizada en la zona templada del país la provincia se presenta como territorio mediterráneo y continental, de clima árido a semiárido, con una variabilidad de las precipitaciones desde los $100 \mathrm{~mm}$ en el extremo noroeste hasta los $400 \mathrm{~mm}$ en el sector sureste, arrojando un promedio de $220 \mathrm{~mm}$ para el territorio provincial. Los vientos húmedos provenientes del Atlántico precipitan escasa humedad por los más de $1.000 \mathrm{~km}$ de distancia que deben recorrer y las masas de aire provenientes del Pacífico (distante sólo a $170 \mathrm{~km}$ ), precipitan en la Cordillera de los Andes, ingresando a la Argentina como vientos secos y cálidos, conocidos regionalmente como Zonda. 
Desde el punto de vista hidrológico, el agua es proporcionada por cinco ríos que han sido configurados por sus respectivas cuencas hidrológicas y que poseen un régimen típico de montaña, aportando su mayor caudal en la primavera-verano con el deshielo de las altas cumbres. El agua es aprovechada para la generación de energía, el consumo humano y el abastecimiento de la amplia red de riego de los oasis.

Respecto al Subsistema socio-económico, las fuerzas más dinámicas de la provincia se articulan en torno a un modelo agroindustrial vitivinícola en los oasis. Las zonas no irrigadas de montaña y de planicie albergan mayormente actividades de subsistencia (especialmente actividades ganaderas extensivas débilmente integradas a los circuitos de la economía mendocina), actividades extractivas mineras e hidrocarburíferas (de gran incidencia en la economía provincial) y actividades turísticas. Estas zonas no irrigadas son expulsoras de población y presentan graves procesos de desertificación, los que afectan la vida cotidiana de sus habitantes e inciden en sus posibilidades de desarrollo futuro. Esta situación se ve agravada por el problema de la tenencia de la tierra pues la mayoría de los pobladores son ocupantes ilegales, no poseedores de derecho sobre la tierra que trabajan (IADIZA, 2004). Fenómenos climáticos como las sequías, el granizo, las heladas, el viento Zonda y la inversión térmica, así como tormentas de nieve en las montañas, son condicionantes climáticos limitantes para el desarrollo productivo y los asentamientos humanos. A estos debe sumarse la presencia de riesgos naturales como los sismos, aluviones, remoción en masa, actividad volcánica e incendios, principalmente. La combinación de riesgos naturales, factores climáticos y geomorfológicos ha determinado ambientes diversos con disímiles posibilidades biológicas y humanas.

Haciendo referencia al Subsistema político-institucional, la provincia de Mendoza se compone de 18 departamentos, los que se agrupan en Regiones conforme a los principales Oasis de Riego (ver gráfico $\mathrm{N}^{\circ}$ 1).

A fin de proceder a caracterizar a Mendoza como una provincia de tierras secas, se procede a incorporar conceptos vertidos en el Documento titulado "Subsistema físico-biológico o natural de la provincia de Mendoza" (Abraham et all, 2013), el que sirvió de insumo para la elaboración del PPOT² (2014).

El mencionado documento define para la provincia Unidades Ambientales de Referencia (UAR) las que constituyen áreas homogéneas tanto en sus características físicas y biológicas como en los usos del suelo que las caracterizan, lo que permite identificar potencialidades y restricciones.

Dicho documento identifica siete UAR en la provincia de Mendoza, las que se mencionan a continuación:

- Montañas altas: con asentamientos dispersos, actividades turísticas, recreativas, deportivas, conservación, ganadería extensiva y actividades mineras.

- Montañas medias: con asentamientos dispersos, actividades turísticas, recreativas, deportivas, conservación, ganadería extensiva y actividades petroleras y mineras

- Montañas Bajas: cerrilladas pedemontanas y huayquerías, meseta del Guadal con asentamientos dispersos, actividad ganadera extensiva, petrolera, minera y turística recreativa.

- Valles intermontanos: con asentamientos concentrados y aislados, servicios, cultivos, ganadería extensiva, actividades mineras y turísticas.

- Piedemontes: con asentamientos dispersos y concentrados, ganadería extensiva, grandes emprendimientos agrícolas con aprovechamiento de agua subterránea y superficial, actividades petroleras y mineras y procesos de urbanización en expansión.

- Oasis o llanuras modificadas: con grandes núcleos urbanos, usos agrícolas, de servicios e industriales. Representan sólo el 3\% de la superficie total provincial.

- Llanuras no irrigadas: con asentamientos dispersos, ganadería extensiva mayor y menor, explotación petrolera, grandes emprendimientos agrícolas con aprovechamiento de agua subterránea.

- Mesetas y volcanes de la Payunia: con asentamientos aislados, ganadería extensiva, explotación minera y petrolera y actividades de conservación.

\footnotetext{
${ }^{2}$ PPOT: Plan Provincial de Ordenamiento Territorial de Mendoza. Presentado en Legislatura en mayo de 2014 y aún no es sancionado como Ley.
} 


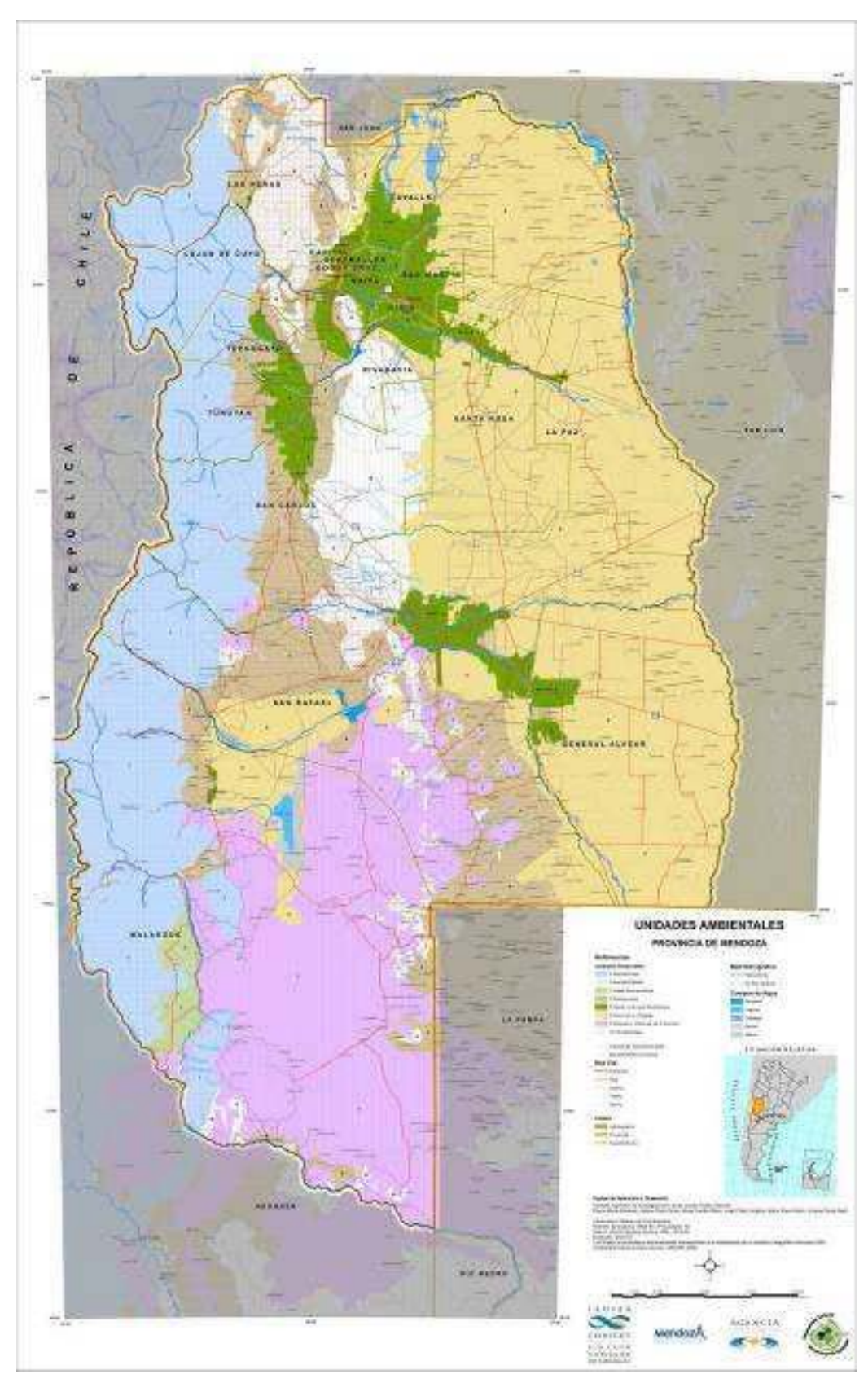

Gráfico $N^{\circ}$ 1: Unidades ambientales de referencia de la provincia de Mendoza Fuente: Subsistema físico natural. IADIZA, CCT-Mendoza (2013).

Dado el enfoque de la presente tesis, se procede a hacer hincapié en la UAR denominada Oasis o llanuras modificadas pues comprenden las tierras secas irrigadas que albergan los principales asentamientos humanos.

\subsection{Las tierras secas irrigadas en Mendoza: oasis para el asentamiento humano}

Las tierras secas irrigadas, también llamadas oasis, constituyen planicies aluviales con altas modificaciones antrópicas entre las que se destaca la irrigación.

Al decir del PAN (2004), los aparatos fluviales que descienden de la cordillera de Los Andes han construido extensos conos aluviales con fértiles suelos que, unidos a las obras de aprovechamiento hídrico y sistematización del riego, han generado importantes unidades productivas. Se trata de la conquista, a través de la irrigación, de fragmentos de desierto para crear un espacio agrícola. El enorme esfuerzo requerido para la conquista de estas tierras queda justificado por su alta calidad, posicionándose a la cabeza de las mejores tierras agrícolas.

En toda la Argentina los oasis de riego suman 1.500 .000 has y surgieron aprovechando la dotación de aguas superficiales y subterráneas (PAN, 2004). Los oasis se caracterizan por el aprovechamiento intensivo 
de las tierras para la producción frutihortícola. En todos los casos los asentamientos urbanos se localizan sobre estos mismos espacios produciendo una competencia por el uso del suelo que actúa, generalmente, en detrimento de los usos agrícolas afectando negativamente las economías locales. Los ejemplos más significativos son los oasis de las provincias de Mendoza, San Juan y los de los valles patagónicos.

En Mendoza, los oasis representan 360.000 hectáreas sistematizadas para riego, lo que equivale a que aproximadamente el $3 \%$ de la superficie total provincial de tierras secas se encuentre irrigada. Por constituir los oasis espacios adaptados para la vida en enclaves de aridez, la población se asienta sobre los mismos generando la concentración del $97 \%$ de la población provincial, lo que implica albergar la mayoría de los asentamientos humanos.

Los oasis mendocinos comenzaron su desarrollo a partir de los lugares que presentaban la combinación de dos importantes elementos: agua y buenos suelos aptos para el desarrollo de la actividad agrícola. Estos elementos se encuentran naturalmente asociados puesto que son los ríos quienes arrastraron sedimentos que se depositaron en superficies reducidas del territorio provincial en forma de conos aluviales ${ }^{3}$ entre las zonas pedemontanas y las llanuras.

Respecto a la producción, en los oasis mendocinos encontramos producción primaria (cultivos de vid, frutas, hortalizas, que se comercializan tanto en el mercado local, nacional e internacional), secundaria (agroindustrias: bodegas, industrias conserveras, secaderos de frutas) y terciaria (comercio y actividad de servicios).

Son cuatro los oasis que se encuentran en la provincia, como puede apreciarse en la figura siguiente:

a) Oasis Norte: irrigado por el río Mendoza y el río Tunuyán inferior

b) Oasis Centro o Valle de Uco: irrigado por el río Tunuyán superior

c) Oasis Sur: irrigado por los ríos Diamante y Atuel

d) Oasis de Malargüe: irrigado por el río Malargüe

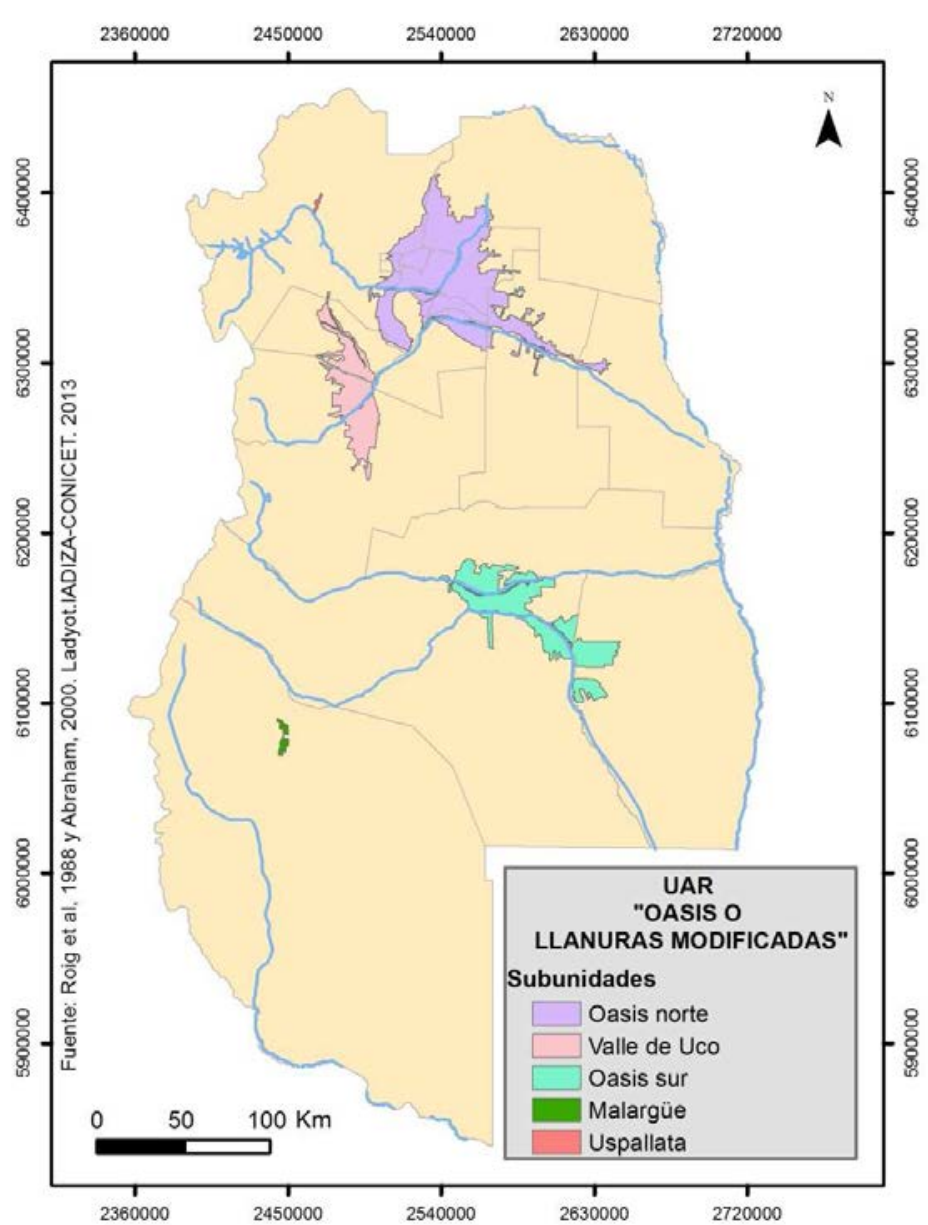

Gráfico N²: Unidades Ambientales de Referencia Oasis o llanuras modificadas, provincia de Mendoza. Fuente: Subsistema físico natural. IADIZA, CCT-Mendoza.

\footnotetext{
${ }^{3}$ Conos aluviales: depósito de sedimentos transportados por los ríos debido a la pérdida de fuerza de arrastre de los mismos, cuando su curso los lleva a terrenos de menor pendiente. La granulometría es mayor cerca del punto de quiebre de pendiente, disminuyendo a medida que se aleja de éste. La forma cónica está dada por los divagues del río en la llanura.
} 


\subsection{Los Oasis y su evolución histórica}

Según informe de la DOADU (Dirección de Ordenamiento Ambiental y Desarrollo Urbano), en el período indígena sólo puede hablarse de oasis en el Norte de la provincia, donde los Huarpes se encontraban asentados. Este grupo aborigen fue el primero en sistematizar el uso del agua para el riego de los cultivos. Su economía de subsistencia se complementaba con la caza, la pesca y la recolección del fruto del algarrobo, principalmente.

A mediados del Siglo XVI comienza el período Colonial con la llegada de los españoles, los que se apropian de estas tierras de gran aptitud agrícola asentándose en ellas. Se procede a la distribución de parcelas y al mejoramiento del sistema de riego produciéndose maíz, trigo, hortalizas y uva, con la que se elaboran los primeros vinos.

La ciudad de Mendoza, con escasa población hasta fines del siglo XVIII, se funda en el Oasis Norte en las cercanías del canal Cacique Guaymallén y se constituye en centro administrativo de una red muy dispersa de pueblos y caseríos, puesto que la mayor parte de la población habitaba en zonas rurales.

A fines del Siglo XIX y principios del XX, con la llegada del ferrocarril a la provincia se produce el ingreso de los inmigrantes europeos, los que se incorporaron principalmente a las labores agrícolas, extendiéndose la superficie cultivada. En esta Etapa, se intensifica el cultivo de la vid abandonándose paulatinamente el cultivo del trigo, ya que se ponen en producción las fértiles tierras de la región pampeana cubriendo la demanda necesaria.

En cuanto a la ocupación del centro y sur de la provincia, los centros poblados se consolidan recién a fines del Siglo XIX cuando las campañas militares controlan la amenaza que los aborígenes de la zona constituían para la población blanca.

\subsection{Los problemas ambientales en una provincia de tierras secas}

Para los autores Abraham y Rodríguez Salas (1999), la provincia de Mendoza posee distintivas cualidades ambientales pero al hallarse ubicada en la Diagonal Árida de la República Argentina, se hace necesaria una mirada atenta a los diferentes problemas que amenazan o afectan en mayor o menor medida sus recursos. Es decir, por constituir Mendoza una provincia de tierras secas resulta indispensable la incorporación de enfoques sistémicos, integrales e integrados a fin de abordar la problemática de la misma tendiendo a la conservación de los distintos ecosistemas y a la planificación del desarrollo con altos niveles de sostenibilidad.

Debido a la condición de fragilidad ambiental de las tierras secas, en la base de los problemas ambientales de la provincia de Mendoza se encuentran los desequilibrios territoriales, manifestados en la concentración económica y demográfica. Esta concentración es típica de los asentamientos de las zonas áridas y semiáridas, con recursos limitados de agua y suelo. En la medida en que el desarrollo provincial tuvo una cierta escala, esta situación no era conflictiva. Sin embargo, en los últimos años el crecimiento acelerado y las expectativas que la sociedad provincial tiene en relación con el desarrollo regional, justifican una optimización y un ordenamiento de este modelo hacia un sistema más equilibrado espacialmente y socialmente más equitativo, que conlleve un uso más racional de los recursos.

En función de los problemas ambientales que aquejan a la provincia, resulta necesario mencionar aquellos vinculados a los procesos de urbanización que inciden en Mendoza, los que se detallan a continuación:

a) Desequilibrio territorial por procesos de concentración relacionados con el desborde urbano y el éxodo de la población rural.

b) Desertificación por deforestación, sobrepastoreo; inadecuadas políticas de cultivo, incendios en ecosistemas de montaña, piedemonte y llanura; crecimiento urbano sobre área frágiles; migración y abandono de tierras; actividades extractivas sobre todo minera y petrolera.

c) Pérdida de áreas agrícolas de alto valor económico (competencia por el uso del suelo por el creciente proceso de urbanización, degradación de canales de riego por el efecto de aguas claras, incendios generalizados, destrucción de vegas y mallines, salinización, y revenimiento)

d) Riesgos naturales (aluvionales, sísmicos, volcánicos, de degradación de suelos y desertificación). Se mitigan o potencian de acuerdo a las modalidades de la ocupación humana y sus formas de organización.

En función de lo antedicho, uno de los principales problemas que afecta a las tierras secas es el crecimiento urbano sobre áreas de fragilidad ambiental.

Por ello se hace necesario delinear enfoques específicos que tiendan a definir de qué modo pueden crecer las ciudades insertas en oasis de modo sostenible y con el menor impacto posible en las ya fuertemente impactadas áreas ambientales frágiles de oasis irrigados. 


\section{EL AGUA EN MENDOZA}

La provincia de Mendoza se ha generado a partir de procesos de interacción entre naturaleza y sociedad desarrollados a lo largo de más de quinientos años, siendo el factor central de este proceso el manejo de los recursos hídricos escasos (Torres, E. y otros, 2004).

En la explicación del desarrollo de la irrigación en esta provincia, la historia y la geografía confluyen: las primeras acequias fueron construidas por aborígenes huarpes cuyas obras aprovecharon los conquistadores españoles. Esto evidencia la valoración del agua como recurso estratégico para el desarrollo de las actividades humanas, lo que devino en la institucionalización de esta visión del recurso concretada en la sanción de la Ley de Aguas (1884).

Los avances institucionales y legales respecto de los recursos hídricos fueron claves en la reconversión de la economía provincial de fines del Siglo XVIII y principios del XIX, cuando se produce el paso de una economía pastoril-ganadera a una economía vitivinícola. Esto requería de la ampliación de la frontera agraria, lo que fue posible gracias a los esfuerzos de sistematización del aprovechamiento hídrico realizado en las últimas décadas del siglo XIX y las primeras del XX, que también implicó grandes avances institucionales, organizacionales, legales y políticos para la construcción del llamado "modelo vitivinícola tradicional".

En los últimos años, la situación ha cambiado pues la vitivinicultura tradicional, a causa de crisis recurrentes, se está reconvirtiendo hacia la llamada "nueva vitivinicultura", orientada a la calidad y al mercado externo. En consonancia, el área regada se extendió considerablemente, la actividad industrial se incrementó y el proceso de urbanización ha dado lugar a la formación de un área metropolitana de casi un millón de habitantes y a una constelación de centros urbanos intermedios y menores que se distribuyen en una malla densa que se despliega dentro de los oasis provinciales. Estas transformaciones evidencian mayores demandas hídricas y una fuerte competencia en los usos del suelo, generándose conflictos en las escasas tierras secas irrigadas.

En la actualidad y a causa de lo mencionado, se observa la necesidad de reflexionar sobre la gestión del agua a fin de concebir su manejo de un modo integral, lo que llevará a la definición de políticas públicas más racionales y sustentables.

\subsection{El agua y la configuración del territorio: los asentamientos humanos}

El agua constituye un elemento estructural en la organización del territorio provincial mendocino (DGI, 2003).

Por ello, al analizar la evolución de la ciudad se puede observar una fuerte dependencia al sistema de riego y al sistema aluvional, pues ya desde tiempos prehispánicos se organiza a partir del aprovechamiento y sistematización de los cursos de agua naturales en relación con las pendientes.

El sistema de conducción de agua configura una vasta red hídrica que está organizada sobre la racionalidad propia del recurso agua. La misma condicionó la configuración de otras redes o tramas estructurantes del territorio como los caminos y los asentamientos humanos, desarrollando edificaciones y cultivos, principalmente.

La agricultura dependió de la utilización del riego artificial por canales y acequias, lo que requirió de asociaciones coordinadas entre los pobladores, forjando el concepto de cultura del agua.

Es decir, el territorio mendocino se estructuró a partir del agua, comprendiendo la construcción de una red de distribución jerárquica (río, canal principal, hijuela y acequia), la concreción de obras o mecanismos para controlar los caudales y posibilitar la distribución (diques, azudes, esclusas, compuertas, desagües y otros), el control del uso y el mantenimiento de la red y una temprana legislación sobre lo agrario (relaciones de trabajo, uso del agua y demás).

A raíz de lo mencionado, el oasis (tierras secas irrigadas) en el cual la ciudad se configura como centro, aparece modulado y ordenado sobre la base de la estructura hídrica y se vincula estrechamente a otros elementos de infraestructura, como la red vial, y a factores naturales, como las pendientes del terreno.

\subsection{El agua en la ciudad de Mendoza}

En las ciudades, la importancia de esta base hídrica puede observarse en el desarrollo urbano, el que no siguió una ley arbitraria, como lo es en el Caso de la Ciudad de Mendoza.

El trazado fundacional de Mendoza procuró aprovechar las facilidades de un terreno pedemontano con suave pendiente suroeste-noreste, por el cual el agua de riego escurre naturalmente. Esto pone en evidencia que el conquistador español se instaló sobre las áreas de riego de los huarpes, adoptando sus prácticas de riego y ampliando paulatinamente el horizonte de cultivo, del que partió el primitivo asentamiento. 
Es decir, en la ciudad colonial el sistema de aprovisionamiento de agua para riego y consumo humano era realizado por medio de la misma red hídrica de canales, que se ramificaba en una serie de acequias que atravesaba las manzanas en el sentido de la pendiente del terreno. Ese sistema compartido, de riego y provisión de agua para consumo humano, perduró hasta fines de 1870, época en que se sistematizó la provisión de agua potable mediante un sistema propio.

A partir de 1880 y a causa de epidemias de enfermedades como el cólera, se realizan las conexiones domiciliarias de agua corriente a la mayoría de los edificios públicos, como en el caso de los hospitales. Primero fue la Ciudad Nueva, luego la Ciudad Vieja y progresivamente, los suburbios. En ciertas zonas rurales, aún en la actualidad, se sigue usando la acequia de riego para captar agua, la que se deja decantar para poder ser usada en el consumo humano.

Por todo lo mencionado, puede decirse que la historia del agua en Mendoza está fuertemente vinculada con los esfuerzos de sobrevivir en un ambiente desértico, evidenciado en la sistematización del recurso y en la construcción de una verdadera cultura del agua.

En función de la manera en que históricamente se ha configurado el territorio mendocino, producto de la conjunción entre soporte ambiental frágil de tierras secas y la sistematización del agua realizada desde épocas pre-hispánicas, es que podría decirse que de la interacción entre naturaleza y sociedad se ha plasmado un particular modelo de ocupación del territorio donde en las escasas tierras secas irrigadas (los oasis) conviven la producción y los asentamientos humanos. Esto trae aparejado que en la actualidad y a causa de los diferentes procesos de ocupación del territorio que se han producido y se siguen produciendo, se configure un modelo territorial de fuerte concentración de población y actividades, evidenciado por la existencia de tupidas y concentradas redes de asentamientos humanos y redes de infraestructura, entre las que se destacan las redes viales y de servicios básicos, principalmente.

\section{LOS PROCESOS TERRITORIALES Y LA CONFIGURACIÓN DEL SISTEMA URBANO: SU INCIDENCIA EN EL CRECIMIENTO URBANO}

Conforme se ha manifestado, la interacción espacio-sociedad genera procesos de ocupación propios en cada territorio. Si bien los procesos de urbanización responden a una dinámica universal que existe desde hace miles de años, en las últimas décadas se generaliza y se impone sobre otros modelos de organización social y espacial, poco más de un siglo en los países avanzados.

La Revolución Industrial constituye un elemento clave que marca un antes y un después en la evolución de todo este proceso. Antes de desarrollarse el sistema productivo industrial, la ciudad era una forma minoritaria de asentamiento que experimentaba oscilaciones con épocas de esplendor y otras de declive, pero que mantuvo durante siglos unos tamaños, unas morfologías y unas estructuras sin grandes cambios. Las transformaciones introducidas por el nuevo sistema de producción y los avances tecnológicos producidos por éste, provocaron que la ciudad crezca, se generalice y se convierta, dinámicamente, en la forma de organización obligada y propiciada por la eficacia del sistema económico.

Un aspecto importante es poner de manifiesto las interrelaciones existentes entre las características de las sociedades que las construyen y las habitan, y las propias ciudades en cuanto constituyen elementos de un territorio y formas específicas de organización espacial.

También es importante enunciar la pervivencia que tiene para los grupos sociales el organizarse en ciudades y una serie de implicaciones que esto trae aparejado, como la mayor capacidad de generar innovaciones y la aparición de economías de aglomeración.

Otro aspecto fundamental producido en el último siglo es el crecimiento espacial de las ciudades, debido a que constituye la forma en que se plasma físicamente la urbanización, reflejando en el espacio la estructura y las características sociales (organización política, estructura económica, desarrollo tecnológico, ideas urbanísticas dominantes, pautas del consumo del espacio urbano, entre otros) que configuran un entramado de estrategias tejidas por los distintos agentes sociales que participan en el proceso.

Es de remarcar el hecho que la urbanización es un producto social, se desarrolla dentro de unas ciertas estructuras, está guiada por intereses individuales o de grupos y evidencia las desigualdades y las controversias sociales, se desarrolla sobre un medio físico que actúa permanentemente como factor diferenciador. Resulta muy importante destacar que el medio físico plantea diversas problemáticas que no pueden ser ignoradas, en pos del desarrollo sostenible.

Una consideración especial debe tenerse respecto a las transformaciones que experimentan los sistemas de asentamientos, es decir cómo se van configurando las redes de ciudades en relación con los procesos de urbanización y cómo aparecen nuevas formas de organización espacial (conurbaciones, áreas metropolitanas, regiones urbanas) que siendo específicamente urbanas adquieren aspectos que las diferencian claramente.

En función de todo lo descripto, resulta importante destacar las interdependencias que se producen entre la organización y el desarrollo de los sistemas de ciudades y las estructuras económicas, en los distintos 
modelos de urbanización considerados. Es de destacar que entre los objetivos de la política de desarrollo regional, suele ocupar un lugar muy destacado la vertebración del sistema de ciudades, mediante distintos tipos de medidas.

Además, en Latinoamérica las ciudades grandes y medianas presentan centralización relativa, es decir, se centralizan el comercio y los servicios y se descentralizan la industria y la residencia. Esto queda evidenciado en el fenómeno de fragmentación territorial ocurrido en los últimos años en la periferia de las mismas y generado por la aparición de nuevos barrios, tanto de operatoria pública como privada y por asentamientos inestables, que ocasionaron la urbanización de áreas de fragilidad ambiental como los espacios rurales y naturales.

Esta fragmentación, ha generado procesos de segmentación social evidenciado en que los nuevos barrios se configuran como islas, aislados del contexto y negando las posibilidades de vinculación con el mismo, pues presentan contundentes limitantes que acrecientan la separación y diferenciación de su entorno.

Los procesos de ocupación de la periferia, han generado crecimiento por extensión de la ciudad, sin tener en cuenta la fragilidad ambiental de su soporte. Este avance de la urbanización no ha sido acompañado por descentralización de funciones administrativas, educativas, de salud y comerciales, principalmente, lo que genera masivos movimientos pendulares diarios, que provocan la saturación de las principales vías de conexión y del centro de las ciudades.

Es decir, el crecimiento por extensión de la ciudad ha generado grandes impactos tanto en el área central como en la periferia de la urbe. Sintetizando, en el área central se ha producido pérdida del tejido histórico y generación de vacíos urbanos carentes de identidad, y en la periferia, la aparición de barrios (de ricos y de pobres) sin la descentralización de los servicios necesarios para su funcionamiento.

También cabe citar otro modo en que crecen las ciudades y que responde a la densificación de las áreas centrales e intermedias. Este proceso ha generado un mejor aprovechamiento de la infraestructura instalada y de los servicios existentes.

Los problemas y las oportunidades que presentan las ciudades en la actualidad, producto de determinados procesos territoriales que las generaron, influyeron, desarrollaron y/o renegaron, constituyen verdaderos desafíos sobre los cuales urge trabajar, con criterio de sostenibilidad.

\subsection{Jerarquización del sistema urbano de la provincia de Mendoza y relación existente entre rangos de centros urbanos}

En la provincia de Mendoza, los centros urbanos, de distintas jerarquías, se agrupan en la escasa superficie que conforman los oasis, estructurándose el territorio como un sistema de centros urbanos concentrados en las tierras secas irrigadas desde donde organizan la totalidad del territorio mediante la función urbana que cada uno cumple.

Por tratarse de un territorio que presenta a su población y actividades agrupadas en unos pocos puntos del espacio, presenta de modo concentrado una densa red de caminos en los oasis, la que conecta rápidamente todos los puntos del mismo. Por el contrario, para la conexión entre oasis y con otros puntos del país y el extranjero se utilizan rutas que atraviesan aisladamente las grandes extensiones de territorio.

Como todo sistema urbano, los centros en la provincia de Mendoza poseen una jerarquía propia producto del rol que cada uno desempeña en el territorio. La APOT ha desarrollado en el PPOT (2014) la jerarquía de nodos urbanos provinciales en la cual se clasifican los asentamientos urbanos en rangos según su cantidad de población y función propia dentro del sistema urbano provincial.

En el Primer Rango aparece el Área Metropolitana de Mendoza, constituyendo la principal ciudad de la provincia. Cabe aclarar que la misma se encuentra integrada por las cabeceras de los departamentos Capital, Godoy Cruz, Guaymallén, Las Heras, Luján y Maipú, la que surgió del conjunto de localidades que, originariamente aisladas, crecieron hasta transformarse en la principal metrópolis del Oeste de la República Argentina. Este centro urbano, que actualmente alcanza el millón de habitantes, constituye el cuarto a nivel nacional y articula el sistema urbano provincial y el de la Región de Cuyo, influyendo sobre el resto de las provincias que integran el Oeste de Argentina: San Juan, San Luis y La Rioja (esta última incorporada en los últimos años).

En el Segundo Rango se ubican las ciudades cabeceras de las Regiones provinciales, apareciendo San Rafael como centro comercial y de servicios de la Región Sur, San Martín como centro de la Región Este y Tunuyán cumpliendo la misma función en el Valle de Uco.

En el Tercer Rango se ubican el resto de las cabeceras departamentales, las que funcionan articuladamente con el nodo cabecera de su región pero dependiendo de él. Las mismas constituyen centros de servicios de sus propios departamentos, de los que dependen otros centros departamentales menores. 
Al Cuarto Rango lo conforman centros urbanos menores que dependen de los nodos del Tercer Rango, es decir de sus cabeceras departamentales, y funcionan como centros de abastecimiento y servicios del área rural circundante.

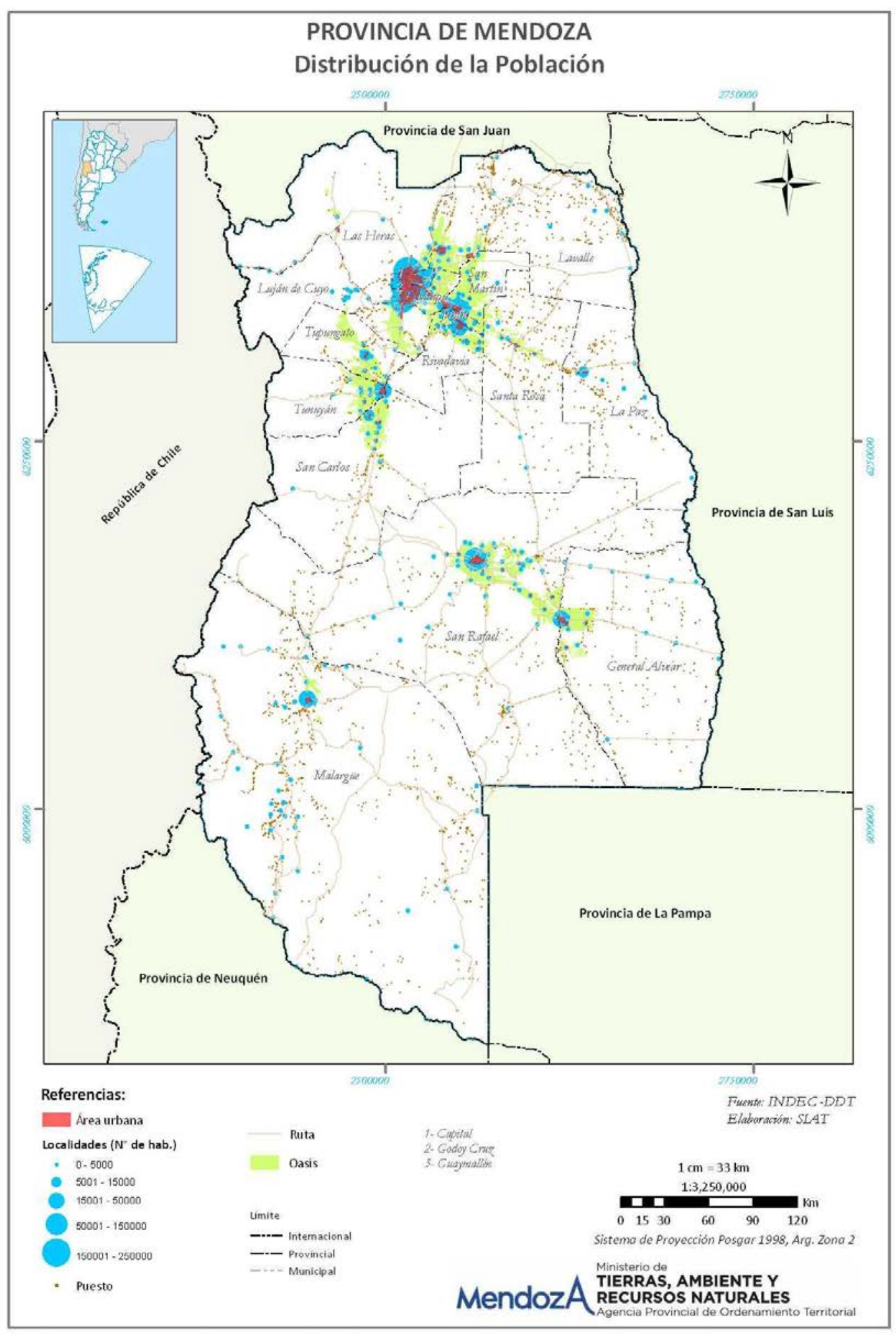

Gráfico $\mathrm{N}^{\circ}$ 3: los oasis y el sistema urbano provincial.

Fuente: Agencia Provincial de Ordenamiento Territorial, PPOT, provincia de Mendoza (2014). 
Conocer la jerarquía de cada uno de los centros dentro del sistema urbano provincial permite elegir los apropiados para abordar el Estudio de Caso propuesto para la presente tesis. Es decir, los centros urbanos seleccionados posibilitan analizar las condiciones actuales que presentan respecto al crecimiento urbano a fin de definir los lineamientos para el crecimiento urbano sostenible en tierras secas.

A partir del análisis detallado de la jerarquía de nodos que componen el sistema urbano provincial, se arriba a varias conclusiones:

1ro) Existencia de un fuerte desequilibrio entre los diferentes rangos de nodos a causa de la cantidad de población, representando saltos de 10 veces entre un rango y otro. Es decir, El nodo principal del Área Metropolitana de Mendoza presenta 10 veces más población que San Rafael, considerado un nodo de 2do rango. A su vez, el nodo de San Rafael posee 10 veces más población que el nodo Tupungato, el que constituye un nodo de 3er rango. Esta misma diferencia se observa entre el nodo Tupungato y el centro rural de San Pedro del Atuel, ubicándose en el último rango de centros poblacionales.

2do) Esta marcada diferenciación entre rangos de centros urbanos permite determinar que uno de los grandes problemas que presenta el sistema de centros urbanos provincial es el marcado desequilibrio territorial, lo que evidencia una acentuada concentración de población, actividades y funciones en los centros mayores.

3ro) Esta marcada diferencia entre cada uno de los rangos de centros urbanos permite decir que Mendoza presenta un modelo de región subdesarrollada, definida por Vinuesa Angulo y Vidal Domínguez (1991) como una estructura muy jerarquizada en la que la ausencia de centros subregionales y comarcales anula las posibilidades de difusión al no alcanzarse los umbrales de demanda necesarios para la aparición de bienes y servicios.

\subsection{El crecimiento urbano en el Área Metropolitana de Mendoza:}

Se elige como Estudio de Caso el Área Metropolitana de Mendoza (AMM), tomando como Variables e Indicadores claves respecto al crecimiento urbano de la misma, los siguientes:

- $\quad$ El consumo de suelo urbano por habitante

- $\quad$ Las densidades de población

- Los tejidos residenciales en áreas de expansión urbana:

- Loteo formal

- Grandes parcelas residenciales

- Vivienda social

- Villas y asentamientos

- Vacíos urbanos

\subsubsection{El consumo de suelo por habitante y la expansión urbana}

Este indicador permite mostrar la tendencia generalizada al fuerte crecimiento de la superficie urbanizada en contraste con un crecimiento medio de la población y, como consecuencia, un marcado aumento en el promedio de superficie urbanizada por habitante, durante los últimos 20 años. En el AMM, el promedio de consumo de suelo por habitante creció un 52 \%, pasando de 118 m2/hab. en el año 1991 a 227 m2/hab. en el año 2010 (Atlas ID, 2012).

Uno de los fenómenos más marcados es el aumento de la demanda de suelo residencial, en la medida que los sectores de ingresos medios y altos han optado en los últimos años por desplazar su residencia principal a la periferia de la ciudad, adoptando tipologías residenciales de baja densidad que no superan los 60 habitantes por hectárea; al mismo tiempo que los procesos de verticalización en las áreas centrales no están acompañados necesariamente de un aumento de densidad residencial sino del incremento de las superficies destinadas a servicios y la construcción de vivienda para resguardo de valor, con altas tasas de vacancia.

Del análisis de la información producida, se observa un generalizado aumento del consumo de superficie por habitante, sin distinción de jerarquía urbana o pertenencia regional de los casos. Se trata de un proceso que ha sido identificado y caracterizado en contextos muy diferentes a nivel mundial.

Esta tendencia tiene como consecuencia una mayor dificultad de los gobiernos locales para proveer a la población de equipamientos, infraestructuras y servicios urbanos básicos, a lo que se suman los efectos ambientales de la expansión, vinculados al consumo energético, la pérdida de suelo destinado a la producción agrícola, las dificultades en materia de movilidad, etc.

Este patrón de crecimiento con alto consumo de suelo implica la conformación de una ciudad cada vez más fragmentada con, por una parte, grandes extensiones de territorio destinadas a la residencia de los sectores de mayores ingresos y dejando, por otra parte, espacios desvalorizados, ambientalmente críticos y desprovistos de los atributos de la urbanización, para los sectores de menores ingresos. 
La evolución de este indicador plantea la necesidad de diseñar políticas públicas e instrumentos de gestión territorial que apunten a contener la expansión urbana indiscriminada, a encontrar formas de densificación que se integren a los tejidos urbanos existentes, y a generar una redistribución equitativa de los costos y beneficios de la urbanización.

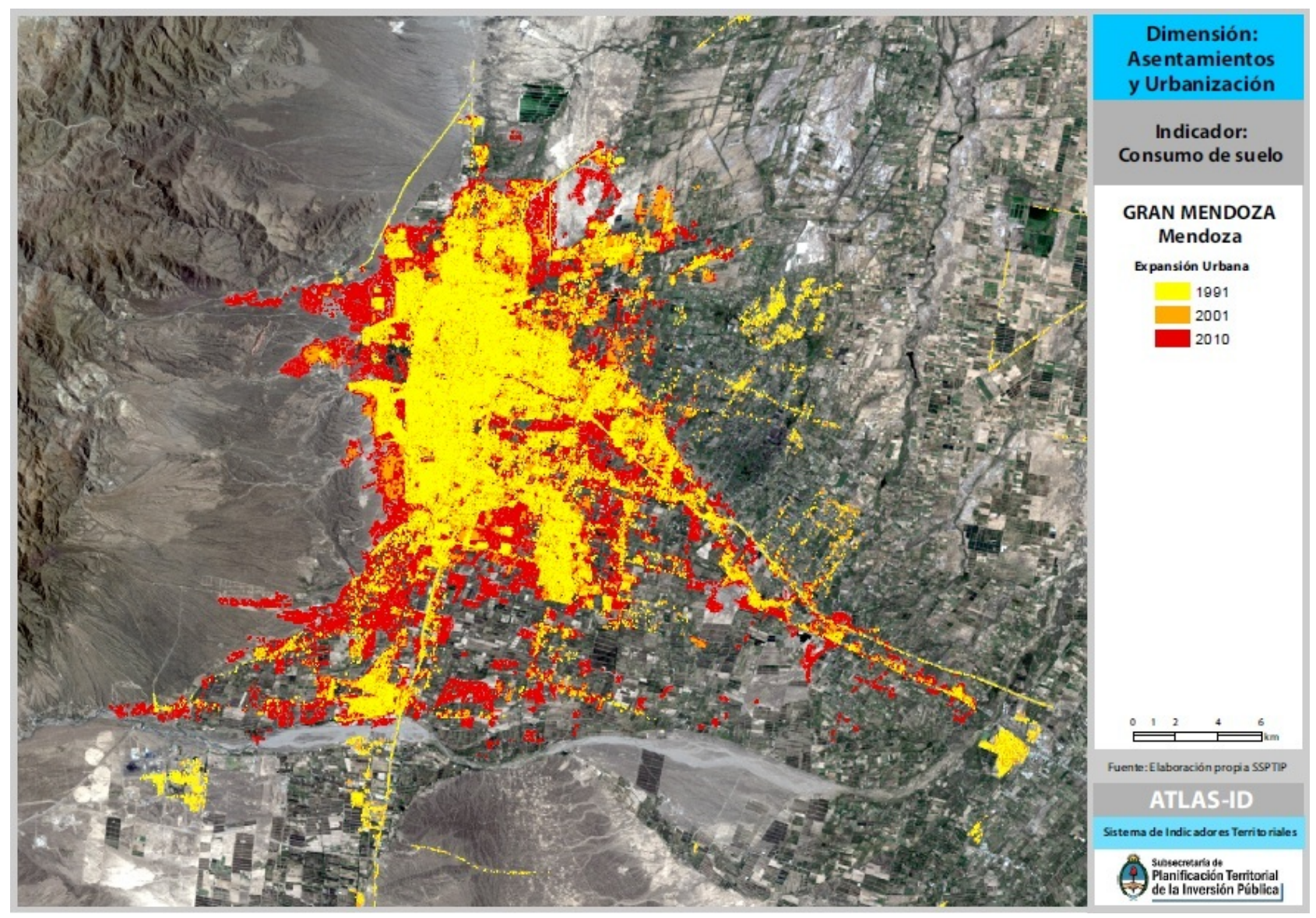

Gráfico $N^{\circ}$ 4: el indicador consumo de suelo urbano y la expansión urbana.

Fuente: Atlas ID, Sistema de indicadores territoriales. Subsecretaría de Planificación Territorial de la Inversión Pública (2012).

\subsubsection{Las densidades de población}

Respecto a este indicador, se observa un descenso de la densidad de población a lo largo del período considerado (1991-2010). En el AMM, la densidad de población descendió un $48 \%$ en los últimos veinte años, como consecuencia de que la superficie urbanizada aumentó un $133 \%$ mientras que, para el mismo período, la población registró un aumento del $21 \%$. Es decir que, el crecimiento del AMM se ha producido mediante un patrón por el cual crece mucho más en superficie que en población.

Este notable descenso de la densidad, fenómeno observado a nivel mundial, trae aparejado el aumento en los gastos vinculados con la provisión de servicios urbanos, tales como la recolección de residuos, el transporte público, la cobertura de los equipamientos educativos, de salud, administración y seguridad, etc. A esto deben agregarse los costos ambientales por la pérdida de suelo absorbente, la constante pérdida de suelo productivo en el entorno inmediato de las ciudades, el mayor consumo de energía para acceder a lugares cada vez más lejanos y la conformación de una ciudad socialmente más segmentada por la calificación diferencial del territorio y la consecuente dificultad de los sectores de menores ingresos para acceder a suelo urbanizado.

Esta constatación plantea la necesidad de adoptar políticas públicas e instrumentos adecuados a fin de conducir los procesos de crecimiento urbano, con el objeto de construir ciudades inclusivas, ambientalmente sustentables y económicamente viables. 


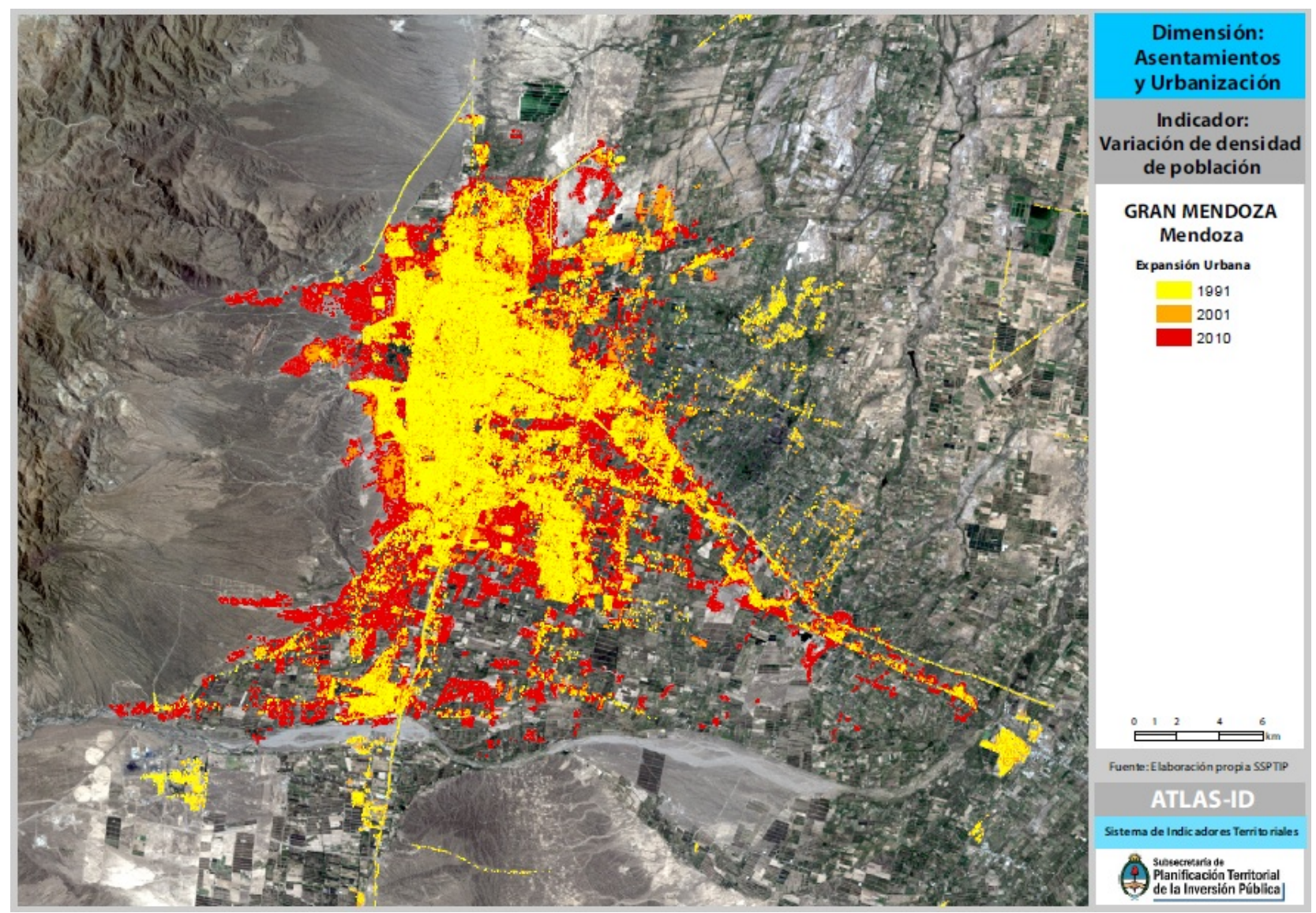

Gráfico N 5: variación de densidad de población.

Fuente: Atlas ID, Sistema de indicadores territoriales. Subsecretaría de Planificación Territorial de la Inversión Pública (2012).

\subsubsection{Los tejidos residenciales en áreas de expansión urbana:}

Este indicador muestra los tipos de tejidos residenciales producidos en las áreas de expansión urbana en los últimos veinte años, en el AMM.

Los resultados del análisis confirman las tendencias en relación con un patrón de expansión de baja densidad y discontinuo, que genera ciudades insostenibles económicamente, insustentables ambientalmente y fragmentadas socialmente.

En el promedio de la muestra, el tipo de tejido que ocupa mayor superficie es el identificado como Grandes parcelas residenciales, de muy baja densidad (menos de 40 habitantes por hectárea), que engloba urbanizaciones cerradas, loteos de grandes dimensiones y quintas, y ocupa un $44 \%$ del perirubano del AMM.

En segundo lugar se encuentra la categoría analítica Vacíos urbanos, lo que acentúa el patrón de crecimiento discontinuo y contribuye a la reducción de la densidad, significando el $29 \%$ de la superficie de esta área de expansión urbana.

Estas dos categorías mencionadas reúnen, en conjunto, el 73 \% de la superficie del área de expansión en el promedio de la muestra y son las que dan los rasgos principales del modelo de expansión urbana dominante.

En tercer lugar se posiciona el Loteo formal, cuya trama urbana es regular, compuesta por lotes de 8 a 10 $\mathrm{m}$ de frente por 30 a $50 \mathrm{~m}$ de fondo y con una densidad neta aproximada entre 60 a $130 \mathrm{hab} / \mathrm{ha}$., alcanzando el $17 \%$ de la superficie del perirubano.

La categoría Vivienda social, que presenta densidades de hasta 200 hab/ha, tiene una presencia no tan significativa como las anteriores, contribuyendo, en muchos casos, por sus localizaciones periféricas (a menudo separadas de la trama urbana consolidada), a incrementar las discontinuidades.

Finalmente, la categoría con menor representación es la de Villas y asentamientos, con solamente un 2 \%, que presenta las mayores densidades en áreas de expansión, aunque sin superar los $300 \mathrm{hab} / \mathrm{ha}$. 


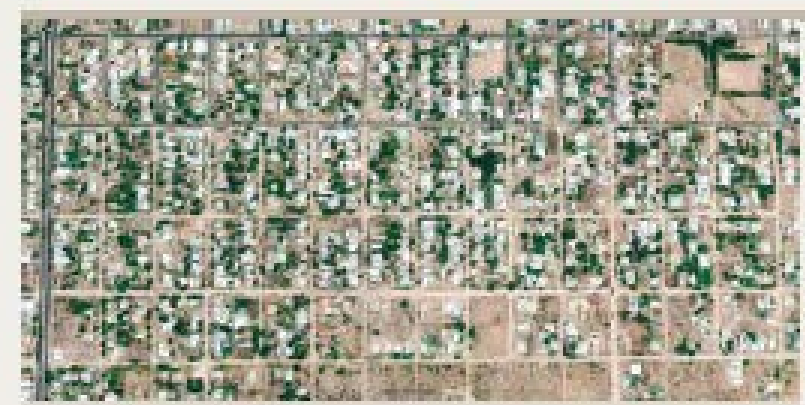

Tipo 1. Loteo formal

Trama urbana regulas, compuesta par lotes de 8 a no metros de frente par 30 a 50 metros de fondo. Densidad neta aproximada: 60 an 130 habitantes/hectarea.
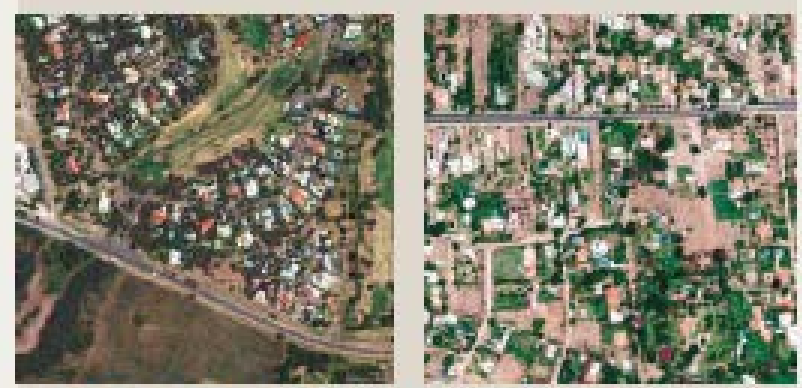

Tipo 2. Grandes parcelas residenciales

Sectores de segunda residencia o residencia principal en grandes parcelas con acreso dinecto desde la trama vial o en urbunizaciones cemadas. En general sin provisión de servicios puiblicos de agua y doacas. Densidad neta aprovimada: menos de 40 habitantes/hectarea.
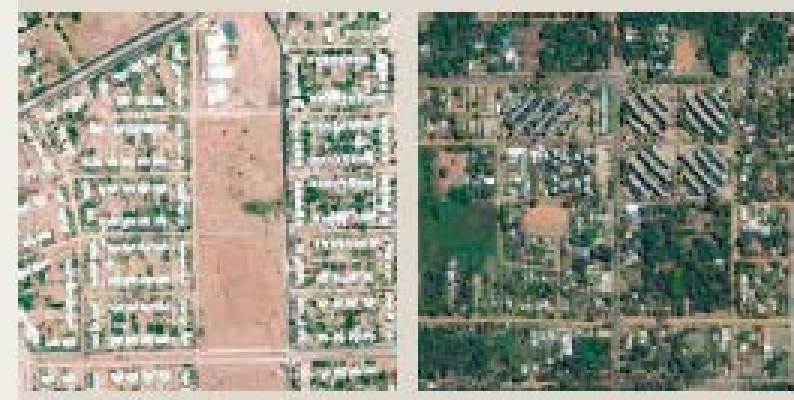

Tipo 3. Vivienda social

Viviendas individuales o colectivas construidas por iniciativa püblica, en general con provisión de infraestructuras y equipamienfos puiblicos. Densidad neta apraximada. entre noo y 600 habitantes/hectarea.

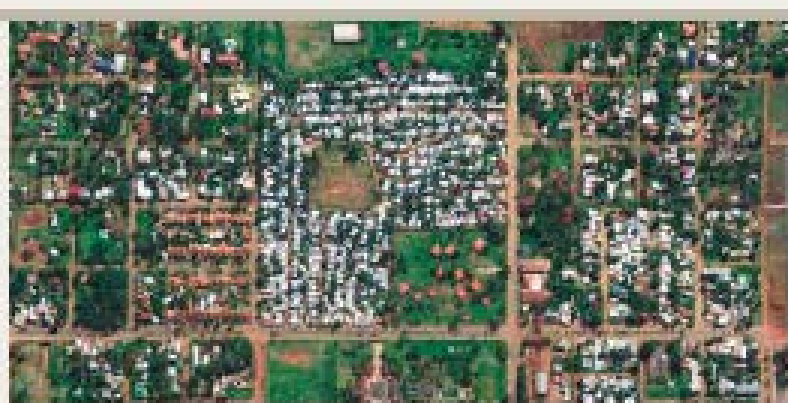

Tipo 4, villas y asentamientos

Densidad neta apravimada: 300 habitantes/hectarea.

Ocupaciones de temenos fiscales o privados sin reguiarización daminial Viviendas autocanstruidas En general, no cuentan con servicios sanitarios por las dificultades de regularización y trazado que presentan.

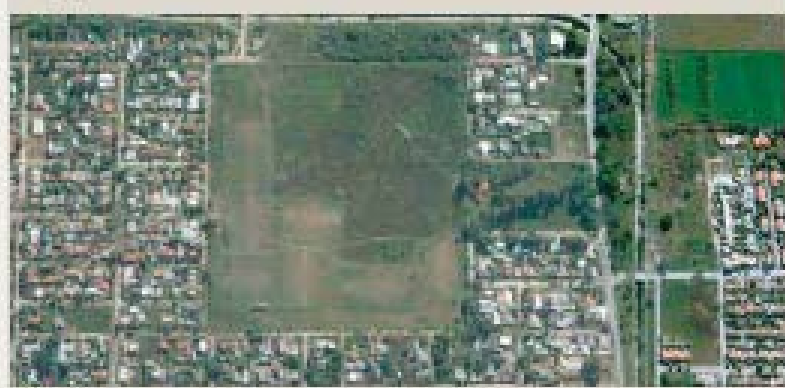

Tipo 5. Vacios urbanos

Grandes parcelas $\sin$ use, con tres o mas lados linderos a la trama urbana existente.

Gráfico $N^{\circ}$ 6: los tipos de tejidos residenciales en el área de expansión urbana.

Fuente: Atlas ID, Sistema de indicadores territoriales. Subsecretaría de Planificación Territorial de la Inversión Pública (2012).

En los últimos veinte años, las periferias de las ciudades, que por sus condiciones de lejanía al centro eran más baratas y accesibles a los sectores de menores ingresos, se han convertido en áreas atractivas para los sectores de ingresos medios y altos, tornando aún más difícil la posibilidad de acceso a suelo urbanizado de los sectores económicamente más vulnerables. 


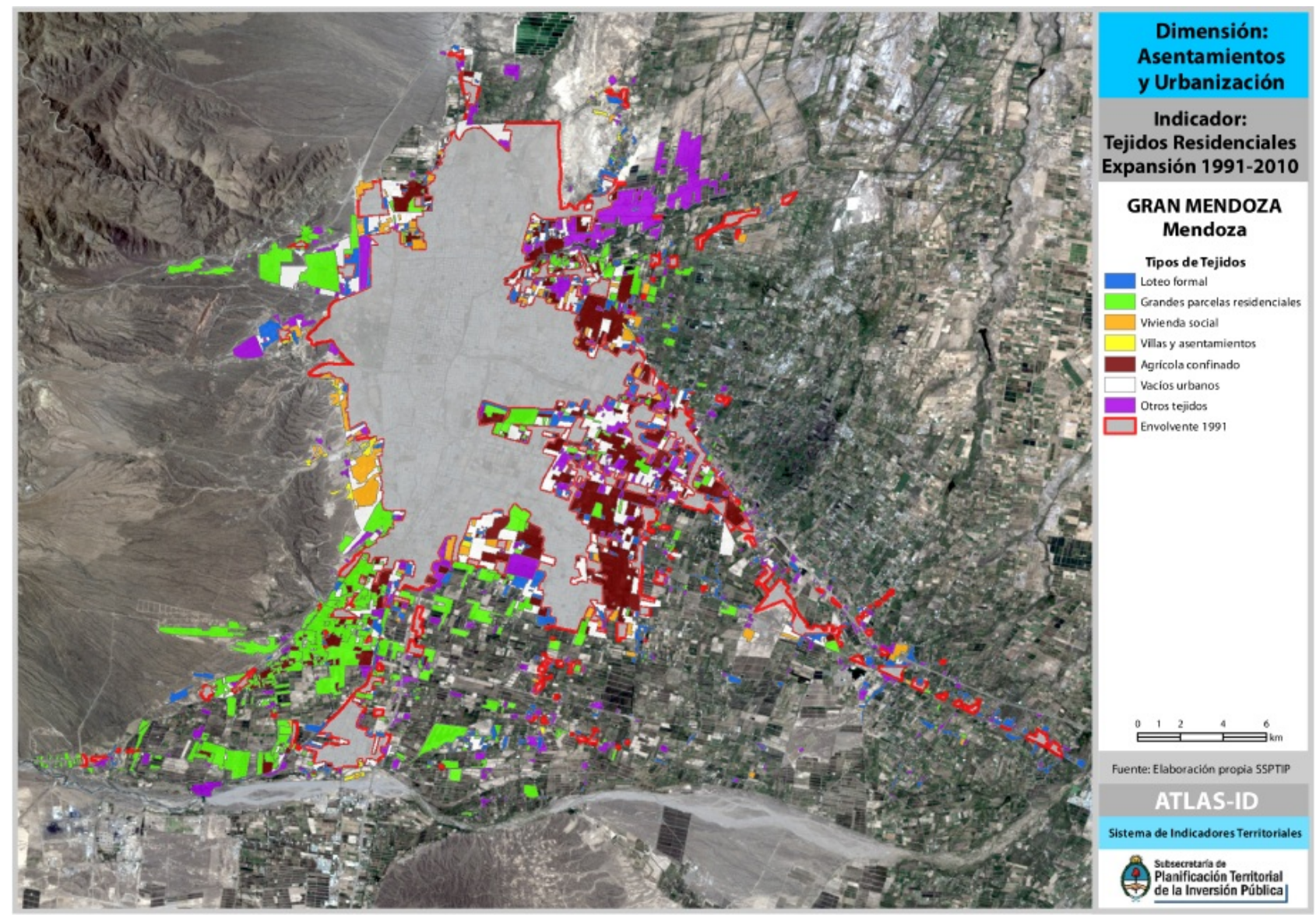

Gráfico $N^{\circ} 7$ : el indicador tejidos residenciales en áreas de expansión urbana.

Fuente: Atlas ID, Sistema de indicadores territoriales. Subsecretaría de Planificación Territorial de la Inversión Pública (2012).

\section{Conclusión: los principales procesos territoriales que configuran el sistema urbano actual}

En función de lo analizado, se observa que los nodos urbanos de la provincia de Mendoza, principalmente el nodo constituido por el Área Metropolitana de Mendoza, presentan como forma prioritaria de crecimiento urbano la extensión de la mancha urbana, frente a un bajo porcentaje de crecimiento por densificación de la misma.

Esto trae aparejado que todos los asentamientos urbanos comparten la misma problemática respecto a la forma de crecimiento por extensión: la fragmentación territorial, ocasionada por formas de ocupación y usos del suelo que no se condicen con las condiciones ambientales de su soporte.

Puede decirse que el proceso territorial común es la fragmentación ya que se observa la misma dicotomía en la escala macro (oasis versus desierto) y en la escala micro (ciudad versus oasis), generando espacios dominantes y excluyentes sobre espacios dominados y excluidos.

Es decir, para evitar que los diferentes nodos urbanos prosigan extendiéndose sobre la escasa superficie de los oasis fragmentando el territorio, se hace necesario delinear políticas de ordenamiento territorial que definan un modo de crecimiento urbano sostenible para Mendoza, que evite la fragmentación del territorio con modos y usos no acordes a la fragilidad ambiental de las tierras secas.

\section{BIBLIOGRAFIA}

\section{Obras completas:}

FERRER REGALES, M. (1992). Los sistemas urbanos. Madrid: Síntesis.

ROCCATAGLIATA, J.A. (2001). Territorio y gestión. Ciudades, regiones y territorios en el espacio mundial globalizado. Buenos Aires: Fundación Hernandarias, Ed. Docencia.

PRECEDO LEDO, A. (1996). Ciudad y desarrollo urbano. Madrid: Síntesis. 
PRECEDO LEDO, A. (2004). Nuevas realidades territoriales para el Siglo XXI. Desarrollo local, identidad territorial y ciudad difusa. Madrid: Síntesis.

PUJADAS, R. y FONT, J. (1998). Ordenación y Planificación territorial. Madrid: Síntesis.

VINUESA ANGULO, J y VIDAL DOMINGUEZ, M.J. (1991). Los procesos de urbanización. Madrid: Síntesis.

\section{Capítulos de libros:}

FERRER, A. (2003). Del crecimiento disperso a la ciudad razonablemente compacta. En A. FONT (comp.), Planeamiento urbanístico. De la controversia a la renovación (135-150). Barcelona: Ed. CUIMPB.

LLOP, C. (2003). De la reserva urbana al proyecto del territorio municipal. En A. FONT (comp.), Planeamiento urbanístico. De la controversia a la renovación (151-168). Barcelona: Ed. CUIMPB.

SABATÉ BEL, J. (2003). Balance y perspectivas del planeamiento urbanístico municipal. En A. FONT (comp.), Planeamiento urbanístico. De la controversia a la renovación (181-204). Barcelona: Ed. CUIMPB.

\section{Revistas}

ÁLVAREZ, A., DROVANDI, A., HERÁNDEZ, J., HERNÁNDEZ, R., MARTINIS, N., MAZA, J., MIRÁBILE, C., MORÁBITO, J., SALATINO, S. Y VARGAS ARANIBAR, A. (2009). El agua en Mendoza y su problemática ambiental. INA-CRA (Instituto Nacional del Agua, Centro Regional Andino). Mendoza.

Documento solicitado por el Ministerio de Medio Ambiente de la Provincia de Mendoza para la capacitación de docentes de la provincia.

BORSDORF, A. (2003). Cómo modelar el desarrollo y la dinámica de la ciudad latinoamericana. Revista EURE (Santiago) v.29 n.86. ISSN 0250-7161.

MONTAÑA, Elma (2008). Las disputas territoriales de una sociedad hídrica. Conflictos en torno al agua en Mendoza, Argentina. Revista Iberoamericana de Economía Ecológica Vol. 9: 1-17

ISSN 13902776. Revista de la red iberoamericana de economía ecológica. URL: http://www.redibec.org/IVO/rev9 01.pdf.

DGI (Departamento General de Irrigación, 2003). Valoremos el agua en Mendoza. En Curso de Educación Ambiental. Gobierno de Mendoza.

\section{Ordenanzas o Decretos:}

Agencia Provincial de Ordenamiento Territorial (2014). Plan Provincial de Ordenamiento Territorial. Provincia de Mendoza, Ministerio de Tierras, Ambiente y Recursos Naturales.

Ley $\mathrm{N}^{\circ} 8051$ de ordenamiento territorial y usos del suelo (2009). Aprobada en la Legislatura de la Provincia de Mendoza, mayo de 2009.

Consejo de Europa (1983). Carta Europea de Ordenación del Territorio. Aprobada el 20 de mayo de 1983 en Torremolinos, España. Conferencia Europea de Ministros Responsables de la Ordenación del Territorio.

Provincia de Mendoza (1884). Ley general de aguas.

Fuentes electrónicas:

ABRAHAM, E. (2008). Tierras secas, desertificación y recursos hídricos. Ecosistemas; revista científica y técnica de ecología y medio ambiente. http://www.revistaecosistemas.net/articulo.asp?ld=531. (Consulta $12 / 01 / 2015)$

ABRAHAM, E. y RODRíGUEZ SALAS, A. (1999). Política ambiental en la provincia de Mendoza. Contenidos y alcances de la programación ambiental. Revista APORTES para el Estado y la Administración Gubernamental. http://www.asociacionag.org.ar/pdfaportes/12/a12_03.pdf. (Consulta: 22/12/2013).

ABRAHAM, E. (2013). Diagnóstico físico-ambiental de la provincia de Mendoza. PID, IADIZA. CCTMendoza. 
ATLAS ID (2012). Sistema de indicadores territoriales. Subsecretaría de Planificación Territorial de la Inversión Pública. http://atlasid.planificacion.gob.ar/

Secretaría de Ambiente de la Nación Argentina. PAN (Programa de Acción Nacional de Lucha contra la Desertificación, 2004). http://www.medioambiente.gov.ar/suelos/programas/pan/default.htm

TORRES, E., MONTAÑA, E., TORRES, L. y ABRAHAM, E. (2004). Problemas del uso del agua en tierras secas: oasis y desierto en el Norte de Mendoza, Argentina. Proyecto CYTED XVII.1 "Indicadores y Tecnologías Apropiadas de Uso Sustentable del Agua en las Tierras Secas de Iberoamérica". LADyOT, IADIZA. Mendoza. 